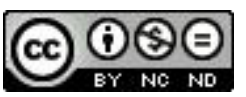

\title{
O Ler e o Escrever na Construção do Conhecimento Matemático no Ensino Médio
}

\author{
Reading and Writing in the Construction of \\ Mathematical Knowledge in the High School
}

\author{
Roberto Alves de Oliveira* \\ Celi Espasandin Lopes**
}

\section{Resumo}

Esta pesquisa teve como objetivo investigar a utilização de diferentes estratégias de Leitura e Escrita no ensino de Matemática do Ensino Médio, e de instrumentos nos quais os alunos externaram as suas percepções durante o processo de ensino e aprendizagem. Para tanto, realizou-se uma pesquisa qualitativa com análise interpretativa sobre as atividades e os instrumentos propostos, os quais foram organizados em um Portfólio. A formulação e a aplicação da pesquisa, bem como a análise dos resultados e as conclusões foram baseadas no enfoque histórico-cultural de Vigotski e estudos sobre a linguagem matemática e a utilização da Leitura e Escrita nas aulas de Matemática, de diversos pesquisadores. As categorias emergentes da análise dos dados foram: a construção do conhecimento matemático, a semântica dos termos matemáticos, os valores demonstrados pelos alunos e a potencialidade das atividades. Os resultados, considerando-se todas as categorias, indicam que o processo pode tornar a relação professor-aluno e aluno-aluno mais interativa e mais efetiva para a construção do conhecimento matemático.

Palavras-chave: Leitura e Escrita. Contextualização. Matemática Ensino Médio. Enfoque Histórico-cultural. Portfólio.

\footnotetext{
"Mestre em Ensino de Ciências e Matemática pela Universidade Cruzeiro do Sul (UNICSUL). Supervisor de Ensino da Rede Estadual de São Paulo, Docente do Ensino Médio na Rede Estadual de São Paulo. Endereço para correspondência: Rua Tiradentes 225, apto 84, CEP: 08673-150. Suzano, SP, Brasil.E-mail: roiveira@yahoo.com.br.

** Doutora em Educação pela Faculdade de Educação da Universidade Estadual de Campinas (FE/ UNICAMP). Professora Titular do Mestrado e do Doutorado em Ensino de Ciências e Matemática da Universidade Cruzeiro do Sul (UNICSUL), São Paulo, SP, Brasil. Endereço para correspondência: Av.Gessy Lever, 915/c.383, CEP: 13272-000. Valinhos, SP, Brasil. E-mail: celilopes@uol.com.br.
} 


\begin{abstract}
The main goal of this study was to investigate the utilization of different strategies of reading and writing in mathematics teaching at the high school level, and of instruments the students could use to externalize their perceptions during the teaching and learning process. A qualitative research methodology was used, with interpretative analysis of the activities and the proposed instruments, which were organized in a Portfolio Book. The formulation and the application of the research, as well as the analysis of the results and the conclusions, were based on Vygotsky's historical-cultural approach and on other studies regarding mathematical language and the utilization of reading and writing in mathematics classes. The categories that emerged from the analysis of the data were the construction of mathematical knowledge, semantics of the mathematical terms, values and the potentiality of the activities. Considering all the categories, the results indicate that the process can make the relationship among teacher and students more interactive and effective for the construction of mathematical knowledge.
\end{abstract}

Keywords: Reading and Writing. Mathematics in Contexts. High School Mathematics. Historical-cultural Approach. Portfolio Book.

\title{
1 Introdução
}

Este artigo decorre de um estudo realizado a partir da verificação, durante a prática docente, de que quando o aluno não consegue interpretar os códigos da linguagem natural, é muito difícil que ele chegue a entender a contextualização dos conteúdos matemáticos e a própria linguagem matemática. Esta consideração encaminhou à questão: Em que medida um processo de intervenção com Leitura e Escrita, nas aulas de Matemática do Ensino Médio, pode ajudar a promover a construção do conhecimento matemático, considerando-se a preocupação com os conteúdos e a sua utilização paralela aos outros aspectos da contextualização? O conceito de contextualização é entendido, aqui, como a utilização de uma grande diversidade de recursos didáticos, meios e estratégias entre os quais: a aproximação da escola com o mundo real, a interdisciplinaridade, as aplicações práticas, as conexões entre os conceitos matemáticos, a História da Matemática, a Resolução de Problemas, os métodos de aprendizagem ativos e interativos etc.

O embasamento teórico da formulação, da aplicação e do acompanhamento da pesquisa, bem como da análise dos resultados e das conclusões, foi feito à luz do enfoque histórico-cultural de Vigotski (1998, 2001), da mesma forma que de estudos realizados recentemente sobre a linguagem 
matemática e a utilização da Leitura e Escrita nas aulas de Matemática, por diversos pesquisadores, como Corrêa (2005), Fonseca e Cardoso (2005), Malta (2004), Mesquita (2001), Pimm (1999), Santos (2005) e Smole e Diniz (2001).

Todos os referenciais utilizados vão ao encontro dos mesmos pressupostos quanto à importância da linguagem natural no tratamento matemático e na construção dos conceitos matemáticos, embora se mostre necessária a preocupação de culminar, sempre, com a utilização da linguagem formal. Por isso, foram propostas neste trabalho várias atividades que atendessem a esses pressupostos. Para que fossem contemplados todos os referenciais teóricos, procurou-se, então, definir atividades bastante variadas, que proporcionassem uma melhor compreensão da linguagem matemática e da semântica dos termos e expressões nas duas linguagens, bem como a expressão por escrito das ideias e do raciocínio dos alunos, a comparação entre a linguagem matemática e a linguagem natural etc. Também, houve a preocupação de propor atividades que contemplassem a interdisciplinaridade e a contextualização dos conteúdos matemáticos, para que elas adquirissem sentido para os alunos e fossem motivadoras para eles.

\section{Metodologia}

\subsection{Construção das informações}

Para responder ao problema de investigação, foi desenvolvida uma pesquisa qualitativa e interpretativa, baseada em um processo de intervenção, no qual o pesquisador é o próprio professor, com o objetivo de analisar e avaliar em que medida as atividades de Leitura e Escrita referentes aos conteúdos de Matemática, assim como os instrumentos utilizados, contribuem ou não para a construção do conhecimento matemático. Por intermédio dos instrumentos utilizados, os alunos puderam externar, ao longo do processo de ensino e aprendizagem, as suas impressões, as suas dúvidas, as suas percepções sobre os conteúdos, como eles foram desenvolvidos, como ia acontecendo ou não a aprendizagem etc.

A pesquisa foi realizada em uma escola da rede estadual, situada na região central da cidade de Suzano, na Grande São Paulo, com duas classes de segunda série e duas de terceira série do Ensino Médio do período matutino, durante os dois primeiros bimestres de 2006, num total aproximado de cento e cinquenta alunos. Ela constou da produção de um Portfólio, durante o primeiro 
semestre letivo de 2006, com atividades relacionadas à leitura e à interpretação de textos, bem como à produção textual, ligadas aos conteúdos matemáticos que foram estabelecidos durante a fase de planejamento do início do ano, servindo como um dos instrumentos de avaliação bimestral.

O Portfólio é definido por Gardner (apud MOULIN, 2002) como um local para colecionar todos os passos percorridos pelo aluno ao longo da trajetória de sua aprendizagem. De acordo com Curi (2002) o Portfólio é cumulativo, o que permite que a avaliação seja um processo contínuo, vivenciado tanto pelos alunos quanto pelo professor. Algumas atividades são selecionadas pelo professor para toda a classe, enquanto outras se constituem no resultado de pesquisas efetuadas pelos próprios alunos, o que faz com que o instrumento seja uma criação individualizada, levando a um senso de apropriação do trabalho pelo aluno.

A primeira atividade do Portfólio, que foi desenvolvida logo no início do ano letivo, foi a Biografia Matemática (adaptado de Santos (2005)). No primeiro dia de aula, foi solicitado ao aluno que fizesse um texto que contivesse: o seu primeiro nome, o bairro onde mora, escola(s) onde estudou, o que gosta de fazer, se trabalha ou não (se sim, onde e o que faz), que profissão pretende seguir, uma experiência positiva com a Matemática, uma experiência negativa com a Matemática.

No início de cada assunto foi feita a Abertura do Tema (adaptado de Santos (2005)), quando era solicitado que os alunos respondessem a questões dirigidas, visando sensibilizá-los para o conteúdo que seria abordado, bem como obter sinalizações de onde e como deveriam ser efetuadas as intervenções do professor, para que elas ocorressem o mais possível na Zona de Desenvolvimento Proximal (ZDP), como definida por Vigotski (2001), facilitando a definição das atividades.

Durante o desenvolvimento de cada tema ou conteúdo, duas atividades foram compulsórias. A primeira foi a elaboração do Diário de Bordo, um formulário a ser preenchido com impressões do aluno sobre o que ia acontecendo nas aulas (adaptado de Passerino, Carneiro e Geller (2005)). Deveriam ser preenchidos, periodicamente: Passos que segui para aprender - Obstáculos que venci ou dificuldades que superei para aprender - Minhas dúvidas, indagações ou dificuldades sobre o tema - Meus sentimentos, descobertas, comentários, opiniões, reflexões, sugestões ou críticas.

A segunda atividade compulsória, prevista durante o desenvolvimento de cada tema, foi a elaboração do Glossário (adaptado de Santos (2005); Smole 
e Diniz (2001)). Foi feito um levantamento coletivo dos termos que os alunos julgavam mais importantes no tema; foi solicitado, em relação a cada um dos temas, que os alunos dessem sua definição e algo mais: exemplos, aplicações, relações com outros termos, interpretações geométricas, curiosidades etc. A definição deveria ser feita com as próprias palavras do aluno, e não procurando em um dicionário ou no livro didático. Quando os termos têm significados diferentes na Matemática e na linguagem cotidiana, deveriam ser registrados os dois significados.

O professor ainda escolheu outras atividades, dependendo do tema, que poderiam ser discutidas em duplas, se necessário, mas elaboradas individualmente: a) Resolução de Problemas (adaptado de Smole e Diniz (2001)); b) Respostas a questões, utilizando apenas a linguagem natural; c) Resolução de Problemas em duas colunas, uma, em linguagem matemática, e, outra, em linguagem natural (adaptado de Mesquita (2001)); d) Leitura de textos paradidáticos, sobre a História da Matemática e outros assuntos matemáticos, com respostas a questões dissertativas; e) Leitura e interpretação de textos de outros contextos (adaptado de Fonseca e Cardoso (2005)); f) Pesquisa e produção de texto, mostrando a utilização da Matemática em outras disciplinas; g) Leitura e análise do jornal como recurso didático (adaptado de Corrêa (2005)); h) Elaboração de mapas conceituais acompanhados de texto explicativo (adaptado de Santos (2005)).

Como fechamento de cada tema, o aluno poderia escolher uma atividade, entre duas possíveis, sendo: a) primeira opção: preencher o Formulário de Fechamento do Tema, com as seguintes questões: Conceito(s) mais importante(s) abordado(s) no tema - Minha principal dúvida com relação ao tema - $O$ que posso fazer para que esta dúvida seja resolvida - Reflexão sobre a importância do tema para: vida diária, profissões, outras disciplinas, outros temas matemáticos etc. (adaptado de Santos (2005)); b) segunda opção: elaborar Carta de Fechamento de Tema, cujo conteúdo é semelhante ao do Formulário, mas com uma linguagem do cotidiano, mais simples, para um parente, conhecido, amigo etc. (real ou imaginário), explicando para ele (ela) o tema estudado (adaptado de Santos (2005)).

O aluno deveria, ainda, incluir no Portfólio os Anexos, que são outros materiais de produção própria (preferencialmente) ou resultados de pesquisas efetuadas por ele (mas com comentários próprios), sobre o tema estudado, podendo escolher entre: avaliações, artigos, recortes, material da Internet, desenhos, poemas, resumos de textos etc.

No término do semestre, deveria ser preenchido o Formulário de Final 
de Semestre, contendo as seguintes questões: Conceito(s) mais importante(s) abordado(s) no semestre - Minha principal dúvida do semestre que ainda permanece - $O$ que posso fazer para que esta dúvida seja resolvida - $O$ que eu achei da elaboração do Portfólio, e sua importância para minha aprendizagem de Matemática (adaptado de Santos (2005)).

Os critérios de avaliação dos Portfólios foram: Periodicidade de registros; Completitude; Organização; Correção dos conceitos matemáticos; Correção da linguagem; Criatividade; Pesquisa e participação nas atividades; Prazo de entrega. Eles foram avaliados mensalmente, mas os conceitos foram atribuídos bimestralmente. Para o conceito a ser atribuído ao Portfólio, em cada bimestre, os critérios de avaliação variavam de 0 a 10, todos com o mesmo peso.

Através do Portfólio, os Alunos produziam e organizavam as atividades que eram propostas pelo Professor-Pesquisador, com o objetivo de facilitar a construção dos conhecimentos matemáticos. Utilizando-se os Registros Docentes, que se constituíam tanto de avaliações formais quanto do exercício da constante observação da evolução ou não dos alunos, o Professor acompanhava e avaliava essas atividades. Por meio do Diário de Campo, o Pesquisador, que era o próprio Professor, anotava como as atividades iam se desenvolvendo, as reações dos alunos, a necessidade de intervenções, as mudanças de rumo etc.

\subsection{Análise das informações construídas}

Foram efetuadas análises quantitativas e qualitativas dos Portfólios elaborados pelos alunos das quatro classes, levando-se em conta o embasamento teórico e a metodologia de construção das informações descritas. Foi escolhida, também, uma amostra aleatória de dezesseis pastas da segunda série, sendo oito de cada classe, para que fosse aplicada a técnica da triangulação. Para Denzin (apud LOPES, 2003), a triangulação consiste na utilização de abordagens diversificadas para obter resultados mais abrangentes, fidedignos e rigorosos na análise das informações.

Neste estudo optou-se por uma triangulação dupla entre atores e técnicas, levando-se em consideração os três agentes (o Aluno, o Professor $e$ o Pesquisador) e os três instrumentos (o Portfólio, os Registros Docentes e o Diário de Campo), que interagiam entre si. Foi feito um cruzamento das informações produzidas pelos três agentes e pelos três instrumentos, buscando- 
se coincidências e/ou divergências entre eles. Essas informações foram analisadas de acordo com quatro categorias emergentes da construção dos dados: o conhecimento matemático dos alunos, como eles lidam com a semântica dos termos utilizados na Matemática, quais são os valores revelados por eles e a potencialidade das atividades.

A construção do conhecimento matemático faz parte da própria enunciação do problema de investigação desta pesquisa. No que diz respeito à semântica dos termos utilizados na Matemática, num trabalho como este, que envolve a utilização tanto da linguagem matemática quanto da linguagem natural, essa categoria de análise não poderia deixar de ser escolhida. A questão dos valores emergiu, também, como uma importante categoria a partir dos dados construídos, já que através de suas leituras e escritas os alunos percebem os valores do professor, bem como transmitem a sua percepção sobre eles e, ainda, os seus próprios valores, de acordo com Bolívar (1995) e Camps (1996). Quanto à última categoria de análise, a potencialidade das atividades desenvolvidas, pode-se recorrer novamente ao problema de investigação, pois ele procura analisar em que medida um processo de intervenção com Leitura e Escrita nas aulas de Matemática do Ensino Médio pode ajudar a promover a construção do conhecimento matemático.

Um exemplo de como foi feita a análise de cada Portfólio por meio da triangulação, acima descrita, pode ser visto no Apêndice A. Além da aplicação dessa técnica, e com o intuito de propiciar uma reflexão sobre a prática pedagógica do professor, definiu-se, para uma análise mais completa, um tema desenvolvido somente na terceira série - a Matemática Financeira -, escolhendose, aleatoriamente, dezesseis alunos, sendo oito de cada classe.

\section{Resultados}

Do total de dezesseis Portfólios da segunda série, que foram analisados mais detalhadamente, percebe-se, através da triangulação dos instrumentos do aluno, do professor e do pesquisador, que as atividades de Leitura e Escrita: a) Foram potencializadoras para a aquisição do conhecimento matemático, para a semântica dos termos utilizados em Matemática e para o desenvolvimento de valores para onze alunos; b) Foram relativamente potencializadoras para um aluno, que apresenta dificuldades em Língua Portuguesa; c) Foram pouco potencializadoras para um aluno, que apresenta dificuldades nos conceitos básicos de Matemática; d) Não permitem uma conclusão para três alunos, que não 
fizeram grande parte das atividades programadas.

No caso dos onze primeiros alunos, mesmo quando eles tinham poucos conhecimentos prévios nos três temas, não apresentaram muitas dificuldades nas atividades, obtiveram bons resultados nas avaliações formais e nos registros do pesquisador, conseguindo mudanças qualitativas na construção e contextualização dos conceitos, no entendimento dos termos matemáticos e na valorização dos temas. Na perspectiva vigotskiana, o professor não passa conhecimento, ou seja, ele deve estimular e promover o conhecimento, para que o próprio aluno venha a construí-lo; propósito, este, que se perseguiu durante toda a aplicação da pesquisa. Para Vigotski (1998) “[...] poderíamos dizer que o que se deve é ensinar às crianças a linguagem escrita, e não apenas a escrita de letras" (VIGOTSKI, 1998, p. 157). Com relação ao décimo segundo aluno, pode-se concluir que os instrumentos utilizados e as atividades realizadas tiveram um resultado razoável, e que a maior parte dos problemas apresentados por ele parece dever-se mais às dificuldades com a Língua Portuguesa e um pouco com os conceitos básicos de Matemática. Quanto ao décimo terceiro aluno, percebeu-se que o processo de registro escrito possibilitou a ele alguma sistematização dos conceitos, mas ainda falta transcender o saber matemático além do senso comum e da resolução de problemas e exercícios.

Já quanto aos três últimos alunos, pode-se concluir que a maior parte dos instrumentos utilizados e das atividades realizadas foi prejudicada pela postura não-participativa dos três nas atividades em geral, não permitindo, assim, uma conclusão sobre a construção do conhecimento e sobre a semântica dos termos. Para Vigotski (2001) as características de cada indivíduo vão sendo formadas a partir da interação constante com o meio, entendido como formado tanto pelo mundo físico quanto pelo social, o que inclui as dimensões interpessoal e cultural. É, então, através desse processo que o indivíduo intervém em seu meio, ao mesmo tempo em que internaliza as formas culturais e as transforma. No caso dos três alunos, as suas resistências quanto à participação nas atividades de Leitura e Escrita, bem como a sua interação não satisfatória com os colegas, durante essas atividades, podem ter comprometido o seu desenvolvimento.

Os resultados obtidos com a utilização de cada um dos instrumentos e atividades do Portfólio, considerando-se todas as análises efetuadas, são comentados a seguir. A primeira atividade do Portfólio, a Biografia Matemática, trouxe uma riqueza muito grande de informações sobre a realidade dos alunos, as suas dificuldades, as suas aspirações etc., informações, essas, que não costumam estar presentes nas aulas de Matemática, o que possibilitou um melhor 
direcionamento da atuação do professor durante o processo de ensino e aprendizagem, à medida que forneceu subsídios para uma prática que levasse em conta o ambiente histórico-cultural do aluno, como a preconizada por Vigotski (1998, 2001). Um exemplo, extraído de uma Biografia Matemática:

Sou péssima na matéria de Matemática, eu gosto de fazer contas, mas me enrolo muito. Eu tenho certeza que o professor entende esse lado, como não sou só eu, muitas pessoas têm dificuldade na matéria, mas o professor está ali para nos ajudar, com a colaboração dos alunos e dos professores aprenderemos muito neste ano, e isso tornará a matéria mais fácil e agradável. (ALUNO No 33,3B).

As questões de abertura dos temas revelaram-se uma ótima estratégia para sensibilizar os alunos para o tema que seria abordado, bem como obter sinalizações de onde e como deveriam ser efetuadas as intervenções do professor, para que elas ocorressem o mais possível na ZDP, facilitando a definição das atividades que seriam desenvolvidas, para que, através da análise e da produção de textos, com o auxílio do professor ou em conjunto com outros alunos, fosse produzida uma Zona de Desenvolvimento Proximal que resultasse numa Zona de Desenvolvimento Real (VIGOTSKI, 2001). Por exemplo, na introdução do tema Matemática Financeira, a questão sobre a diferença entre juros simples e juros compostos revelou, para alguns alunos, uma ZDP propícia para a consolidação desses conceitos:

Não sei, acho que juros simples é um custo menor. E o juros composto é um valor maior que acumulou. (ALUNO No 10 , 3B).

Juros simples são acréscimos que não mudam de valor diariamente, mensalmente ou anualmente permanecem sempre em um igual valor. Juros compostos são acréscimos em cima de acréscimos, ou seja, juros em cima de juros. (ALUNO N 9, 3B).

As diferentes atividades, propostas para o desenvolvimento dos diversos temas, também trouxeram resultados bastante animadores. Por exemplo, a técnica de Resolução de Problemas, da forma como foi aplicada, incentivando o aluno a justificar as suas respostas, a elaborar outras perguntas para o problema proposto pelo professor, a criar seus próprios problemas etc., teve um resultado final positivo, indo ao encontro do que afirma Malta (2004), sobre o desenvolvimento da capacidade de expressão do próprio raciocínio, através da Leitura e Escrita, 
o qual promove o desenvolvimento da capacidade de compreensão da Matemática. Segundo a autora, aprender a ler e a escrever em Matemática é um elemento da ZDP que precede o desenvolvimento real do pensamento e do conhecimento matemático.

A técnica da Resolução de Problemas foi utilizada em Análise Combinatória, com a proposição de problemas que levassem os alunos ao Diagrama de Árvore e ao Princípio Fundamental da Contagem (PFC). Foram propostos pelo professor problemas envolvendo o número de maneiras com que podemos nos vestir com um determinado número de peças de roupas, os sistemas de placas de automóvel atual e antigo e os números de telefone da cidade, após uma pesquisa que os alunos fizeram sobre os prefixos disponíveis. Alguns problemas elaborados por eles para o sistema de placas e a numeração telefônica:

Quantas placas começadas com o meu primeiro nome (ANA) têm se tivessem apenas algarismos diferentes? (ALUNO $\left.\mathrm{N}^{\circ} 4,3 \mathrm{~A}\right)$

No ano de 1971, a nossa cidade possuía um certo volume de carros com placas amareladas. Já em 1991 esse número aumentou 20 vezes. Nesse ano, as placas começaram a ter as letras DK? e podiam repetir as letras e os algarismos. Qual era a quantidade de carros transitando em 1971 e em 1991?(ALUNO No 20,3 A)

Os números de telefones celulares começam com 7, 8 e 9 e têm 8 algarismos. Quantos números de celulares diferentes existem? (ALUNO No 27, 2 A)

As questões propostas para serem respondidas, utilizando apenas a linguagem natural, também os ajudaram a avançar na concepção que eles tinham do tema abordado, na construção dos conceitos relacionados e na compreensão dos significados dos termos nele utilizados, pois essa técnica pode ser um dos caminhos citados por Mesquita (2001), para, através da utilização da escrita em prosa, produzir, fabricar e inventar significados para a linguagem simbólica da Matemática, fazendo com que a aprendizagem da disciplina tenha significado para o aluno. Segundo a autora, a Matemática está permeada por símbolos particulares que denotam abstrações, sendo, então, necessária mais do que somente a decodificação desses símbolos. Para ela, a utilização da escrita em prosa na aprendizagem da Matemática pode sugerir aos alunos que reflitam criticamente sobre suas experiências matemáticas, o que parece ter acontecido com a aplicação da técnica. 
Por exemplo, para a questão: A mãe de um amigo, que mora em Minas Gerais, quando visita o filho em São Paulo, compra aqui um bilhete da Loteria Federal, coisa que não faz lá em Minas. Sua explicação é que quando ela o compra no Estado de São Paulo, suas chances são maiores, já que a maioria dos prêmios sai para cá. Você acha que o raciocínio dela está certo? Por quê?, poucos alunos se deixaram levar pelo raciocínio aparentemente bem elaborado pela senhora (trata-se de um caso real), tendo, logo de início, uma boa percepção da questão, respondendo e justificando corretamente, um indicativo de que o conceito de probabilidade de um evento já estava sendo consolidado entre eles, como mostram os exemplos:

$\mathrm{Na}$ verdade é que em São Paulo há mais compradores de bilhete do que em algumas regiões então parece mais provável que saia aqui, mas não faz a menor diferença comprar aqui ou lá (ALUNO No 36, 2 A)

Não está certo. O resultado da Loteria pode premiar qualquer pessoa do país inteiro com as mesmas chances de ganhar. Se mora em Minas, as chances de ganhar são de uma em milhões e as chances de quem joga em São Paulo também é de uma nos mesmos milhões. (ALUNO N 12,2 B).

Quanto à Resolução de Problemas em duas colunas, uma em linguagem matemática e outra em linguagem natural, os resultados são ainda mais animadores, pois se nota que essa técnica proporcionou mudanças de comportamento muito importantes entre os alunos. Pode-se afirmar que o maior benefício de sua aplicação refere-se à mudança qualitativa que os alunos apresentaram com relação ao significado que eles atribuíam às fórmulas e aos termos matemáticos, ou seja, à sua semântica. A técnica ainda foi bastante útil para o professor, pois através da visualização do trajeto cognitivo mostrado pelos alunos por meio da prosa, ele pôde reconhecer os procedimentos de aprendizagem utilizados por eles, podendo, assim, ajudá-los no processo de construção do conhecimento (MESQUITA, 2001).

Os primeiros problemas propostos para serem resolvidos dessa forma foram em PA e PG. No início, na coluna referente à língua portuguesa, as transcrições eram como uma tradução literal da coluna em linguagem matemática; por exemplo, no primeiro problema de PA, sobre o ano em que Halley avistou o cometa que recebeu o seu nome:

$a_{n}$ igual $a_{1}$ mais $n$ menos 1 vezes $r$; $a_{n}$ igual 1986 ; $a_{1}$ igual $x$; $\mathrm{n}$ igual 5; r igual 76; 1986 igual xis mais cinco menos 1 vezes 
76; 1986 igual xis mais 304; 1986 menos 304 igual xis; $\mathrm{x}$ igual 1782 (ALUNO 26, 2A).

O mesmo aluno, no último problema sobre a fórmula geral da PG (cálculo do valor final da prestação de uma casa paga em sete anos a juros de $10 \%$ ao ano) escreveu:

fórmula do termo geral da PG; determinar $7^{\circ}$ termo da PG; primeiro termo igual 400; razão igual 1,10 que é mesma coisa que $110 \%$; PG tem 7 termos; Aplicação da fórmula: $7^{\circ}$ termo igual 400 vezes ( 1,10 elevado a seis); $7^{\circ}$ termo igual 400 vezes 1,$771561 ; 7^{\circ}$ termo igual 708,62 (arredondamento porque é em Real): que é a prestação do último ano (ALUNO $\left.\mathrm{N}^{\circ} 26,2 \mathrm{~A}\right)$.

Assim, após a utilização da técnica na resolução de vários problemas sobre as fórmulas dos termos gerais da PA e da PG, o referido aluno apresentou uma evolução com relação ao significado das fórmulas e termos matemáticos envolvidos.

Por outro lado, na leitura de textos paradidáticos e de textos de outros contextos, os alunos demonstraram um interesse muito grande, o que propiciou bons resultados, já que se procurou escolher materiais que privilegiassem aspectos mais curiosos e lúdicos da Matemática, bem como a sua relação com o cotidiano e com outras disciplinas. Como exemplo, pode ser citada a utilização do texto de uma corrente recebida pela Internet, para a introdução das Progressões Geométricas, que gerou discussões sobre as novas tecnologias, a ética, a população da cidade, do país e do mundo, entre outros assuntos. Ainda, pode ser mencionada a leitura de um texto sobre a história da Trigonometria, após o que foram respondidas questões sobre os diversos povos e matemáticos que desenvolveram o tema, as suas aplicações, bem como sobre a formação de palavras com os radicais tri, gono e metria, associados a outros radicais, tais como as palavras triângulo, polígono, geometria, hexágono e tridimensional.

A pesquisa e a produção de textos pelos próprios alunos, mostrando a utilização da Matemática no dia a dia e em outras disciplinas também despertaram muito interesse e levaram a bons resultados. Um exemplo foi o trabalho de um aluno mostrando a transmissão do vírus HIV em progressão geométrica. Um trecho do trabalho:

Se cada pessoa infectada com vírus da Aids tiver relações sexuais sem preservativo com outras 2 pessoas os números 
de pessoas infectadas formam uma PG:

(seguem-se os desenhos, feitos pelo próprio aluno, de um rosto masculino na $1^{\mathrm{a}}$ linha; dois rostos femininos na $2^{\mathrm{a}}$ linha; e assim por diante, chegando a 16 rostos masculinos na $5^{\mathrm{a}}$ linha, todos interligados em pares e com o número de rostos indicado em cada linha) (ALUNO N $\left.{ }^{\circ} 11,2 \mathrm{~B}\right)$.

O jornal, como recurso didático, revelou-se um ótimo instrumento para a aquisição e a consolidação de conceitos matemáticos, pois ele desenvolveu nos alunos a capacidade de atribuir significados, bem como a de processar e interpretar criticamente as informações nele veiculadas, estabelecendo maior interação entre a escola, a comunidade e a sociedade (CORRÊA, 2005). Esse recurso foi utilizado principalmente em Matemática Financeira:

Para iniciar esta matéria nós fizemos uma atividade sobre uma notícia de jornal relacionada ao tema que é Matemática Financeira, que foi muito importante para que eu aprendesse essa matéria. (ALUNO No 15, 3B).

Quanto à construção de Mapas Conceituais acompanhados de texto, pôde-se verificar que eles representam um bom início para a introdução desta ferramenta como uma estratégia para a aprendizagem de conceitos matemáticos. A continuidade de sua utilização poderá conduzir à maior facilidade para a sua elaboração por parte dos alunos. De acordo com Novak e Gowin (1999), os Mapas Conceituais servem para tornar mais claro, tanto para o professor quanto para o aluno, as ideias-chave que devem ser focadas para uma aprendizagem específica, já que a maior parte dos significados dos conceitos é adquirida através da composição de proposições que incluem o conceito a ser aprendido. Abaixo, o texto explicativo de um Mapa Conceitual sobre os triângulos retângulos:

Os triângulos retângulos tem um ângulo reto e dois ângulos agudos que se somam gerando os $90^{\circ}$ do ângulo reto. Pode ser simplificado pela fórmula: $\mathrm{B}+\mathrm{C}=90^{\circ}$. Os triângulos retângulos também apresentam a hipotenusa e os dois catetos que são seus lados. A soma dos quadrados dos catetos equivale ao quadrado da hipotenusa sua fórmula é $\mathrm{a}^{2}=\mathrm{b}^{2}+\mathrm{c}^{2}$ que é o teorema de Pitágoras (ALUNO No 11,2 A).

Por sua vez, a pesquisa e a produção dos Anexos, mostrando a presença e a importância dos temas abordados, tanto no cotidiano quanto em outras áreas, 
foram muito úteis para a consolidação dos conceitos envolvidos nos temas, pois mostraram sua aplicação em assuntos nos quais os próprios alunos estavam interessados. Por exemplo, no Anexo de Matemática Financeira de uma aluna, ela apontou que havia um erro no desconto anunciado numa propaganda:

Será propagada enganosa: a promoção acima se refere a um desconto de $35 \%$ sobre 140,00 Reais cujo o resultado final seria 94,00 Reais mais será que esse preço está correto? Veja: $140.0,35=49 ; 140-49=91$. Isso quer dizer que se o preço fosse seguir a risca a taxa de desconto anunciado o curso iria ser 91,00 Reais. (ALUNO Nº 9, 3 A.)

As colocações do professor em sala de aula, enfatizando a relação dos assuntos pesquisados nos Anexos com o tema abordado e com outros temas da Matemática foram fundamentais para essa consolidação e contextualização por parte também dos outros alunos.

Passando a analisar os resultados apresentados pelos instrumentos utilizados no Portfólio, pode-se afirmar que o Diário de Bordo foi muito importante para que o professor pudesse acompanhar a construção do conhecimento pelos alunos, durante o desenvolvimento dos temas, pois da mesma forma que a Biografia Matemática faz, antes do início do processo de ensino e aprendizagem, ele dá voz ao aluno durante o transcorrer desse processo, mostrando as suas necessidades, as suas conquistas, as suas dificuldades, as suas opiniões etc., indo ao encontro das recomendações de Freire (2005) de que ensinar exige saber escutar o aluno e respeitar a sua leitura de mundo.

Por exemplo, no item Passos que segui para aprender, do Diário de Bordo, em praticamente todos os temas a maioria dos alunos considera importante tanto o papel deles próprios quanto o do professor para a sua aprendizagem, destacando, no processo, alguns passos tradicionais: prestar atenção nas explicações do professor, tirar as dúvidas, fazer exercícios, estudar. Já alguns também citaram a importância da ajuda de colegas, o que vai ao encontro dos pressupostos de Vigotski sobre a importância da mediação no processo ensinoaprendizagem.

Com relação ao Glossário, pode-se dizer que a definição dos termos com as próprias palavras dos alunos auxiliou-os na organização das informações, na construção do conhecimento matemático, no aperfeiçoamento da percepção que eles tinham dos termos e no significado que atribuíam a eles. Nos Glossários de todos os temas, em geral, comparando-se as definições com as respostas às Questões de Abertura, pode-se constatar que, no final de cada tema, os alunos 
já apresentavam uma boa noção dos conceitos no seu sentido matemático, tanto nos termos que eram desconhecidos quanto no caso daqueles que eles já conheciam no seu sentido comum, e que conseguiram estender para a Matemática. Parece, assim, ter sido superado o que Pimm (1999) descreve como incongruências e rupturas de comunicação que podem surgir, causadas pela falta de discriminação entre os registros da linguagem natural e da linguagem matemática, já que muitas aulas de Matemática desenvolvem-se em torno de uma mescla de registros das duas linguagens. Uma das causas desse problema, de acordo com o autor, refere-se a certas diferenças de significado existentes entre os elementos dos registros matemáticos tomados emprestados da linguagem natural, e o uso dos mesmos nesta linguagem, fato que tem uma forte influência do contexto histórico-cultural dos alunos. Por exemplo, em Análise Combinatória, nas questões de abertura dos temas os alunos definiam a palavra arranjos no seu sentido comum, como:

Pode ser flores, arranjo de conseguir, por exemplo: eu arranjo para você um livro novo. (ALUNO $N^{\circ} 19,2 B$.) .

Um tipo de arrumar as coisas.(ALUNO N ${ }^{\circ}$ 7, 2B.).

Me lembra música, mas não tem nada a ver. (ALUNO No 11 , 2A.).

Matematicamente não sei explicar, na língua portuguesa vem de arranjar. (ALUNO No 3, 3B.).

Já no Glossário, elaborado mais próximo do final do desenvolvimento dos temas, a grande maioria passou a defini-los no seu sentido matemático:

Quando você tem sequiências diferentes quando a ordem é diferente ou os elementos são diferentes (ALUNO N²,2B) Quando tomamos certa quantidade de números, letras ou outras coisas e temos que escolher alguns e colocar em ordens diferentes (ALUNO N ${ }^{\circ} 4,3 \mathrm{~A}$.).

O Formulário de Fechamento do Tema, da mesma forma que o Diário de Bordo, foi um instrumento bastante importante para que o professor pudesse acompanhar a construção do conhecimento pelos alunos, já que, mais uma vez, foi dada voz a eles, agora na finalização dos temas, mostrando as suas necessidades, as suas conquistas, as suas dificuldades, as suas opiniões etc., indo, novamente, ao encontro das recomendações de Freire (2005), já citadas. Analisando, como exemplo, o fechamento do tema Geometria Espacial, verificamos que, quanto ao conceito mais importante, a maior parte dos alunos 
destaca a construção dos poliedros ou a elaboração dos cálculos relativos a eles, e alguns poucos enfatizam as aplicações práticas, principalmente o cálculo da embalagem mais econômica. Ao apontarem a principal dúvida com relação ao tema, os alunos se dividiram entre afirmar que já resolveram todas as suas dúvidas (ou elas são mínimas) ou que ainda continuam com algumas delas. Sobre o que podem fazer para que a dúvida seja resolvida, a maior parte julga importante o próprio esforço, alguns enfatizam a importância da mediação do professor, enquanto outra parte afirma que não tem mais dúvidas, mas, mesmo assim, alguns apresentam sugestões. Ao refletirem sobre a importância do tema, a totalidade dos alunos reconhece a importância dele para a vida diária, para as profissões e para a aprendizagem de outras disciplinas ou outros temas matemáticos.

A outra opção para o encerramento dos temas, a Carta de Fechamento de Tema, revelou-se um instrumento muito rico para a avaliação do desenvolvimento do aluno proporcionado pelos temas, à medida que apresenta tanto os aspectos afetivos quanto os cognoscitivos envolvidos no processo de ensino e aprendizagem. Pode-se concluir, da análise do fechamento dos temas, que, mesmo levando em conta as dificuldades apontadas por alguns alunos, eles apresentaram mudanças qualitativas na construção dos conceitos envolvidos em cada um. Como exemplo, podemos citar a carta de uma aluna dirigida ao namorado, onde ela aborda, de maneira muito criativa, os conceitos de PA e de PG. Um pequeno trecho dessa carta:

... Achei interessante a PA. Pode não parecer, mas ela está em várias coisas da nossa vida. Olha a fórmula dela, é fácil!!: $\mathrm{a}_{\mathrm{n}}=\mathrm{a}_{1}+(\mathrm{n}-1) \mathrm{r}$; $\mathrm{a}_{1}$ é o $1^{\circ}$ termo, como se fosse o primeiro dia em que a gente ficou; $n$ é o número de dias em que já pensei em você; $r$ é a razão que eu gosto de você; e então $a_{n}$ é o resultado de quanto te amo, que dá um número bem grandão... (ALUNA No 34,2 A.).

Por último, o Formulário de Fechamento do Semestre foi muito importante para o aluno avaliar o seu processo de aprendizagem durante o semestre e o papel desempenhado pelo Portfólio nesse processo. Por exemplo, quanto às principais dúvidas que ainda permaneceram com relação aos temas abordados nas duas séries (Análise Combinatória, Probabilidades, PA/PG, Geometria Espacial, Trigonometria e Matemática Financeira), a maioria respondeu que não restavam mais dúvidas. Já sobre o que eles poderiam fazer para que as dúvidas restantes fossem resolvidas, a mediação do professor e a dos colegas 
revelaram-se muito importantes do ponto de vista dos alunos (33\%), mas as iniciativas próprias, que somadas perfazem $56 \%$, indicam que eles valorizam bastante o exercício da autonomia.

Os resultados obtidos em cada um dos temas desenvolvidos no semestre, para as duas séries, permitem considerar que a interação entre os alunos, o professor-pesquisador e os instrumentos utilizados interferiu positivamente na sistematização do conhecimento matemático que os alunos já traziam intuitivamente, e na mudança qualitativa nos significados que eles, até então, atribuíam a termos utilizados em cada tema. Pode-se dizer que o processo de intervenção com Leitura e Escrita promoveu a construção do conhecimento matemático, possibilitando que os alunos sistematizassem os conceitos além do senso comum. Através das intervenções do professor, gradativamente foram criadas Zonas de Desenvolvimento Próximo e Real, de acordo com o preconizado por Vigotski (2001), permitindo uma mudança nos significados que eles até então atribuíam aos termos utilizados, como, por exemplo, o equívoco que apresentavam na diferenciação entre área e volume e as suas respectivas unidades de medida, na diferenciação entre juros simples e juros compostos etc.

O desenvolvimento dos temas permitiu, ainda, o resgate do exercício da cidadania, por exemplo, através do cálculo de embalagens mais econômicas para o consumidor, da mudança de atitude perante as correntes milionárias e os jogos como o da Mega-Sena, assim como o desenvolvimento de uma postura crítica com relação aos descontos nas promoções, o que se pode verificar no depoimento a seguir:

Bom, deu para perceber que quando aparece um objeto o qual está liquidando com $60 \%$ de desconto com certeza devemos saber o quanto custa realmente esse objeto isso tudo é uma forma de chamar a nossa atenção. (ALUNO ${ }^{\circ}$ 38,3 A.).

Além disso, o desenvolvimento dos temas permitiu, igualmente, a prática da interdisciplinaridade, por exemplo, na aplicação do conceito de densidade no tema Geometria Espacial e no cálculo de probabilidades na Biologia. 


\section{Considerações finais}

A análise dos resultados alcançados com a utilização do Portfólio mostrou que este é um instrumento de grande aceitação pelos alunos, pelos vários motivos que foram apontados por eles mesmos, como mostram os exemplos:

Foi muito interessante a elaboração do Portfólio pois através disso pude perceber o que realmente aprendi, dando minha opinião no seu fechamento. (ALUNO No 7, 2 A.).

É muito bom poder ver uma pasta com suas evoluções e dificuldades superadas no ano e tudo isso em uma pasta muito interessante para mim, as aulas de Matemática esse ano não está sendo só de contas, estou aprendendo coisas que precisei descobrir em mim mesma. (ALUNO No 1,3B.) .

O Portfólio também se revelou muito útil para o professor, à medida que funciona como um elemento de comunicação aluno-professor-aluno, bem como um incentivo à constante reflexão por parte dos dois e à autonomia do aluno.

Com relação ao objetivo que foi estabelecido para a pesquisa, pode-se considerar que foi atingido, já que se analisou e avaliou em que medida as atividades e os instrumentos propostos puderam contribuir para a construção do conhecimento matemático dos dezesseis alunos que constituíram a base documental da pesquisa, dentre os cerca de cento e cinquenta que dela tomaram parte. Retomando-se as categorias de análise emergentes da construção dos dados, pode-se afirmar que, quanto à construção do conhecimento matemático, as atividades de Leitura e Escrita em Matemática parecem ter proporcionado ao aluno maior compreensão com relação aos conceitos matemáticos, tendo sido um facilitador e um potencializador da construção do conhecimento. No que diz respeito à semântica dos termos utilizados na Matemática, as atividades propostas também parecem ter proporcionado ao aluno maior compreensão com relação à linguagem utilizada na disciplina, o que pode ser respaldado através dos vários autores citados no corpo deste trabalho, que têm pesquisado a Leitura e a Escrita nas aulas de Matemática, bem como a linguagem matemática. Falando-se dos valores, é possível afirmar que através de suas leituras e escritas os alunos perceberam os valores do professor, bem como transmitiram a sua percepção sobre eles e, ainda, os seus próprios valores (BOLÍVAR, 1995; CAMPS, 1996). Assim, as atividades parecem ter impulsionado, nos alunos, maior consciência sobre a importância da Matemática na vida diária, nas profissões, nas outras disciplinas, no pleno exercício da cidadania etc. Quanto à 
última categoria de análise, a potencialidade das atividades desenvolvidas, a maioria delas revelou um grande potencial, com destaque para a Resolução de Problemas em duas colunas, para a semântica dos termos matemáticos, assim como a Carta de Fechamento de Tema e os Anexos, para a consolidação e contextualização dos temas.

O que foi comentado acima leva à constatação que o processo de registro escrito nas aulas de Matemática do Ensino Médio, através do Portfólio, possibilitou que a maior parte dos alunos sistematizasse os conceitos além do senso comum, ou seja, ele foi facilitador e potencializador para a aquisição de um saber matemático que transcendesse a resolução de problemas e exercícios para os alunos que não apresentavam muitas dificuldades com o domínio básico da Língua Portuguesa ou com os conceitos fundamentais de Matemática, assim como dificuldades de interação com os colegas ou resistências quanto à participação nas atividades. O desafio para professor é fazer com que esses problemas sejam minimizados ou não interfiram tanto, para que possa haver a construção do conhecimento para todos os alunos. Pode-se, então, concluir que os dados analisados indicam que um processo de intervenção com Leitura e Escrita nas aulas de Matemática do Ensino Médio pode ser um caminho que torna a relação professor-aluno e aluno-aluno mais interativa e, consequentemente, mais efetiva para a construção do conhecimento matemático e, portanto, do conhecimento em geral. Numa perspectiva mais ampla, levando-se em conta os resultados alcançados, a Leitura e a Escrita nas aulas de Matemática do Ensino Médio podem ser apontadas como uma estratégia que contribui para repensar o processo de ensino e aprendizagem desta disciplina, possibilitando aos alunos não apenas a aquisição de conhecimentos e competências, mas, também, convivência e realização individual, através de experiências inovadoras, como recomenda Delors (2003).

\section{Referências}

BOLÍVAR, A. La evaluación de valores y actitudes. Madrid: Grupo Anaya, 1995.

CAMPS, V. Los valores de la educacíon. 4. ed. Madrid: Grupo Anaya, 1996.

CORRÊA, R.A. Linguagem matemática, meios de comunicação e Educação Matemática. In: NACARATO, A. M.; LOPES, C. E. (Org.). Escritas e Leituras na Educação Matemática. Belo Horizonte: Autêntica, 2005, p. 96-99. 
CURI, E. Avaliação e Formação de Professores: propostas e desafios. Educação

Matemática em Revista, São Paulo, v. 1, n. 11A, p. 105-113, 2002.

DELORS, J. Educação, um tesouro a descobrir. São Paulo: Cortez, 2003.

FONSECA, M. da C. F. R.; CARDOSO, C. de A. Educação Matemática e Letramento: textos para ensinar Matemática e Matemática para ler o texto. In: NACARATO, A. M.; LOPES, C. E. (Org.) Escritas e Leituras na Educação Matemática. Belo Horizonte: Autêntica: 2005, p. 66-70.

FREIRE, P. Pedagogia da autonomia: saberes necessários à prática educativa. 31. ed. São Paulo: Paz e Terra, 2005.

LOPES, C. A. E. O conhecimento profissional dos professores e suas relações com Estatística e Probabilidade na Educação Infantil. 2003, 281 f. Tese (Doutorado em Educação) - Faculdade de Educação, Universidade Estadual de Campinas/UNICAMP, Campinas, SP, 2003.

MALTA, I. Linguagem, Leitura e Matemática. In: CURY, H. N. (Org.). Disciplinas Matemáticas em cursos superiores: reflexões, relatos, propostas. Porto Alegre: EDIPUCRS, 2004, p. 41-62.

MESQUITA, C. G. R. A escrita matemática: espaço para aprendizagens que fabricam conhecimentos. 2001. Disponível em: http://www.anped.org.br/reunioes/24/ T1919506565133.doc. Acesso em: 06 ago. 2010.

MOULIN, N. Utilização do Portfólio na avaliação do Ensino a Distância. 2002.

Disponível em: <http://www2.abed.org.br/ visualizaDocumento.asp?Documento_ID=90>. Acesso em: 06 ago. 2010.

NOVAK, J. D.; GOWIN, D. B. Aprender a aprender. Tradução de C. Valadares. 2. ed. Lisboa: Plátano, 1999.

PASSERINO, L. M.; CARNEIRO, M. L. F.; GELLER, M. Diário de Bordo: desenvolvendo a reflexão e autonomia na EAD. Porto Alegre: UFRGS, 2005.

PIMM, D. El lenguaje matemático en el aula. 2. ed. Madrid: Ediciones Morata, 1999.

SANTOS, S. A. Explorações da Linguagem Escrita nas Aulas de Matemática. In: NACARATO, A. M.; LOPES, C. E. (Org.). Escritas e Leituras na Educação

Matemática. Belo Horizonte: Autêntica, 2005, p. 129-140. 
SMOLE, K.S; DINIZ, M. I. S. V. Ler e Aprender Matemática. In: SMOLE, K.S; DINIZ, M. I. S. V. (Org.). Ler, escrever e resolver problemas. Porto Alegre: Artmed, 2001, p. 69-86.

VIGOTSKI, L. S. A formação social da mente: o desenvolvimento dos processos psicológicos superiores. Tradução de J. Neto-Cipolla, L. S. M. Barreto, S. C. Afeche. 6. ed. São Paulo: Martins Fontes, 1998.

VIGOTSKI, L. S. A Construção do pensamento e da linguagem. Tradução de P. Bezerra. São Paulo: Martins Fontes, 2001.

Submetido em Janeiro de 2011. Aprovado em Junho de 2011. 


\section{APÊNDICE A - Análise de Portfólio - Aluno 01}

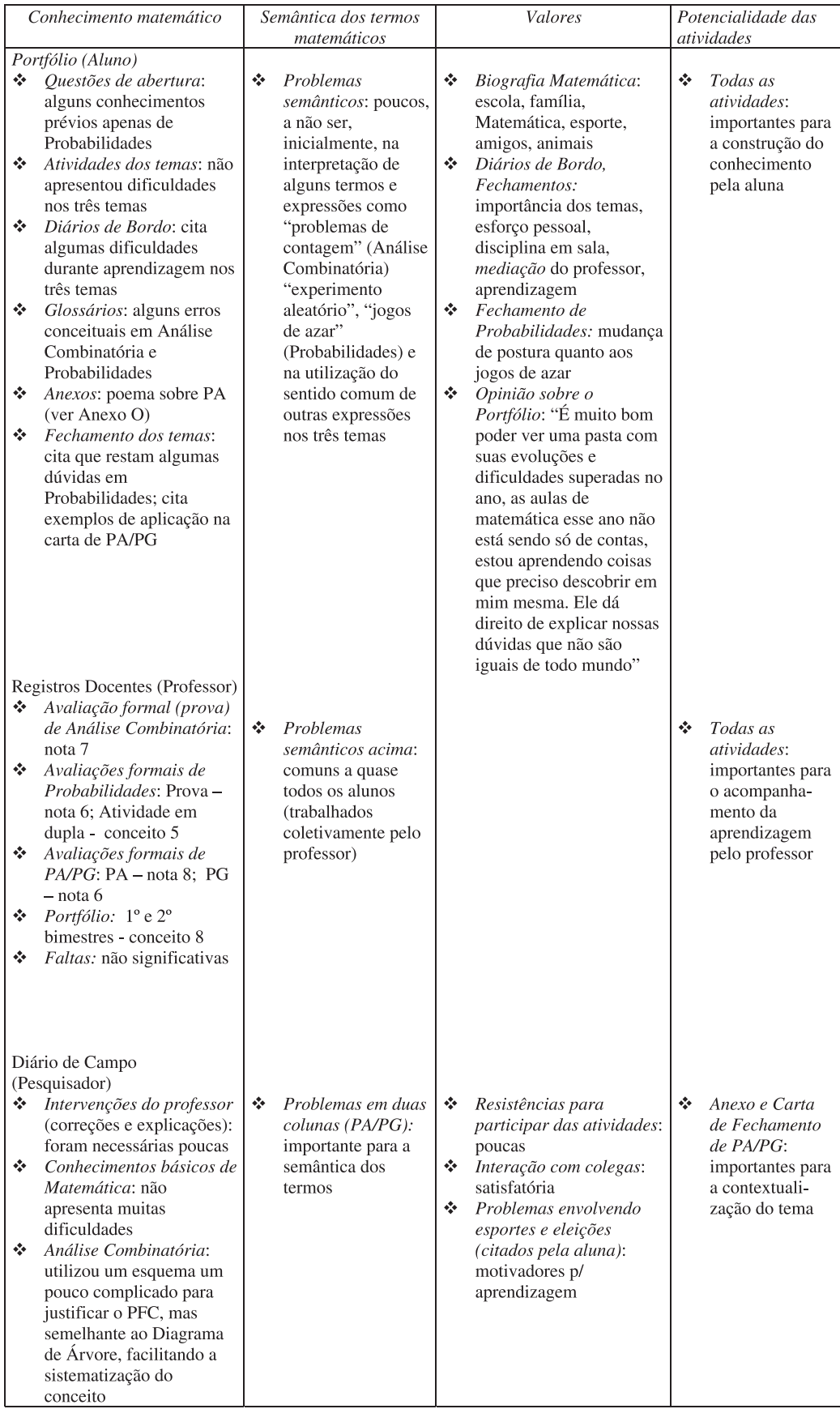

